\title{
Effect of Stress Relief on Pile Capacity in Soft Clay
}

\section{Eram Gilani ${ }^{1}$ *, Mukhtiar Ali Soomro ${ }^{1}$, Tariq Ali ${ }^{2}$, Aqeel Ahmed Sahito ${ }^{2}$ and Abdul Salam Buller ${ }^{3}$}

\author{
1 Department of Civil Engineering, Quaid-e-Awam University of Engineering, Science \\ and Technology, Nawabshah, Sindh, 67450, Pakistan \\ 2Department of Civil Engineering, The Islamia University of Bahawalpur, Punjab, \\ 63100, Pakistan \\ ${ }^{3}$ Department of Civil Engineering, Quaid-e-Awam University College of Engineering, \\ Science and Technology, Larkana, Sindh, 77150, Pakistan
}

\section{Article Type: Article \\ Article Citation: Eram Gilani, Mukhtiar Ali Soomro, Tariq Ali, Aqeel Ahmed Sahito, Abdul Salam Buller. Effect of stress relief on pile capacity in soft clay. Indian Journal of Science and Technology.2020;13(09), 1089-1097.D01: 10.17485/ijst/2020/v013i09/150004}

Received date: February 6, 2020

Accepted date: February 22, 2020

*Author for correspondence: Eram Gilani Veramgilani1995@ gmail.com 9 Department of Civil Engineering, Quaid-e-Awam University of Engineering, Science and Technology, Nawabshah, Sindh, 67450, Pakistan

\begin{abstract}
Objective/methods: Pile load test is commonly carried out at ground level assuming that using sleeve eliminates shaft resistance within the planned excavation area. But these tests do not capture the effect of stress relief due to excavation. So to study its effect on pile behavior, three numerical simulations were carried out using finite element method. The first simulation (L_Ground) was carried out at the ground level. The second simulation (L_Sleeve) was conducted using sleeve in the planned excavation area. The length of sleeve was taken equal to the depth of basement. The third simulation ( $\mathrm{L}_{-}$ Excavation) was carried out after excavation at the formation level. Findings/application: It was found that $Q_{\mathrm{LE}}$ is $85 \%$ of $Q_{\mathrm{LS}}$ so when tests are conducted by using sleeve, pile capacity is over estimated. $Q_{\mathrm{LG}}$ is $74 \%$ of $Q_{\mathrm{LS}}$ which is less than $Q_{\mathrm{LE}}$. Because after excavation, soil particles around the pile are stiffer so capacity is increased. At ground level, at working load shaft carries about $77 \%$ load. When the load is increased and reaches the ultimate value end bearing contributes more than the shaft resistance. On the other hand, for sleeved pile, at working load shaft and end bearing carries about 80 and $20 \%$ load, respectively. But at ultimate load, shaft carries 55\% load which is still greater than that carried by end bearing. While after excavation, at working load shaft carries about $86 \%$ load. When ultimate load is reached the load distribution is similar to sleeved pile. In the case of ground level and excavation, the shaft resistance has been fully mobilized at the load less than $Q_{L S}$ that is about 74 and $86 \%$ of $Q_{L S}$, respectively. These results will help to estimate the pile capacity in a better way.
\end{abstract}

Keywords: Stress Relief, Pile Capacity, Soft Clay. 


\section{Introduction}

These days, tall structures have turned into a need to meet the housing requirements for the ever-increasing population. For such structures, soil must have high bearing capacity to sustain its load. When underlying soil is soft or rock strata are at higher depth, we often require deep foundations. In addition, in tall structures, wind load must also be taken into consideration as it produces lateral pressure that shallow foundation cannot resist and may cause failure. To conquer this issue, deep foundation is required. Pile foundation is one of such foundations. Also, wind load increases with height, so basements are preferred, for which deep excavation is required. When buildings having basement are to be constructed, pile load tests are commonly carried out before excavation at the ground surface. It is assumed that if a sleeve is used within the planned excavation depth, shaft resistance is eliminated. But such a test cannot capture the effects of stress relief on pile behavior. As excavation is a stress release process so the actual scenario is different. Removal of soil due to excavation changes the effective stress on the soil particles, so the behavior of soil particles below the ground level prior to excavation is different from that after excavation. It may affect the pile capacity under the deep excavation. The effect of this stress relief on pile behavior is thus required to be studied. In Ref. [1], Gang et al. studied the effects of stress relief on the pile performance in non-dilative soils. He used finite element analysis to compare the pile capacity before and after excavation in non-dilative soils. Pile capacity was found to be reduced by $45 \%$ and pile stiffness by up to $75 \%$. It was concluded that these effects increase with excavation radius $(\mathrm{R} / \mathrm{H})$ and normalized excavation depth $(\mathrm{H} / \mathrm{L})$. They [2] also conducted centrifuge model tests to study the effect of stress relief on pile behavior in dry sand. It was found that the pile capacity depends on the shaft resistance. As in low friction pile shaft resistance was decreased, its capacity was reduced by $16-20 \%$. While for a high friction pile shaft resistance was more so its capacity was increased by $22-44 \%$. In Ref. [3], Peng studied the effect of stress relief on pile capacity and concluded that stress relief may cause the reduction in shaft resistance. It was found that the capacity of pile with non-dilatants interface can be reduced by $20 \%$ when excavation depth is 20 $\mathrm{m}$. While for a pile with dilatants interface, normal stress acting on pile shaft is increased by dilation of the pile-soil interface. Thus $20 \mathrm{~m}$ of stress relief increases the magnitude of dilation by $30 \%$. In Refs. [4-5], authors studied the response of single pile and group pile to the nearby un-propped excavation in dry dense Toyoura sand. Results show that the pile head conditions and its distance from the retaining wall greatly influence the induced pile bending moment and lateral deflection. In Ref. [6], Finno et al. analyzed the performance of existing foundation and found that the construction of the cut does not cause cracking in pile because the bending moments induced in the pile are not so large. In Refs. [7-9], authors studied the behavior of different piles against lateral displacement. It was concluded that the settlement of end bearing pile and friction pile was similar to the soil settlement at the base level and ground surface settlement respectively but it is valid for idealized cases only. The relative stiffness of the pile to the soil mainly governs the lateral response of pile. In Ref. [10], Mair and Williamson studied the effects of deep excavations and tunneling on pile foundations. He studied the cases where excavation depth adjacent to buildings is extended below the piles and found that the settlement for friction piles was similar 
to the settlement of the ground surface at the position of pile heads. This brief literature review has revealed that the stress relief changes the shaft resistance which affects the pile capacity. In previous studies, pile load tests were carried out at the ground surface, before excavation assuming sleeve completely eliminates shaft resistance. But excavation is a stress release process which may affect the pile behavior. The objective of this research is to compare the pile capacity before and after stress relief due to excavation and to determine the changes in axial load distribution along the pile due to stress relief.

\section{Finite Element Modeling}

\subsection{Types of Analyses}

With the prime objective to study the pile capacity before and after stress relief in soft clay, a three-dimensional coupled-consolidation numerical parametric study was carried out. Three numerical simulations were carried out to obtain the load versus settlement curve and the results of these were compared so as to investigate the effect of stress relief on the pile behavior. The first simulation (L_Ground) was carried out at the ground level without excavation. The second simulation (L_Sleeve) was conducted by using sleeve in the planned excavation area assuming that shaft resistance is eliminated along the sleeve length. The length of sleeve was taken equal to the depth of basement but the excavation effects were not considered in this test. The third simulation (L_Excavation) was carried out after excavation at the formation level. The numerical simulation plan is summarized in Table 1.

\subsection{Mesh and Boundary Conditions Used in Abaqus}

For this study, finite element program Abaqus is used. The $60 \mathrm{~m} \times 60 \mathrm{~m} \times 50 \mathrm{~m}$ FE mesh is used for each numerical simulation. In all cases, pile diameter and length are taken as 0.8 $\mathrm{m}$ and $20 \mathrm{~m}$, respectively. Diameter of pile is $0.8 \mathrm{~m}$ and thickness of diaphragm wall is 0.6 $\mathrm{m}$. The depth of excavation and diaphragm wall are $12 \mathrm{~m}$ and $25 \mathrm{~m}$, respectively. Figures 1 and 2 show the FE mesh and boundary conditions.

Modeling of soil, pile, and diaphragm wall was done by using brick elements i.e. hexahedral element with eight nodes. The props were modeled by using truss elements. Pin support was applied at the base because the movement of base of a soil mass is to be restrained in all the directions. While roller supports were applied at sides so as to restrain the movement of sides. The water table is assumed to be at the ground surface.

TABLE 1. Numerical simulation plan

\begin{tabular}{llll}
\hline Numerical ID & $\begin{array}{l}\text { Embedded pile } \\
\text { length }(\mathbf{m})\end{array}$ & $\begin{array}{l}\text { Excavation depth } \\
(\mathbf{m})\end{array}$ & Remarks \\
\hline L_Ground & 20 & 12 & At ground level \\
L_Sleeve & 20 & 12 & Using sleeve \\
L_Excavation & 20 & 12 & At formation level \\
\hline
\end{tabular}




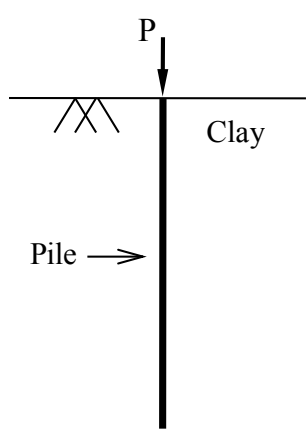

At ground level

(L_Ground)

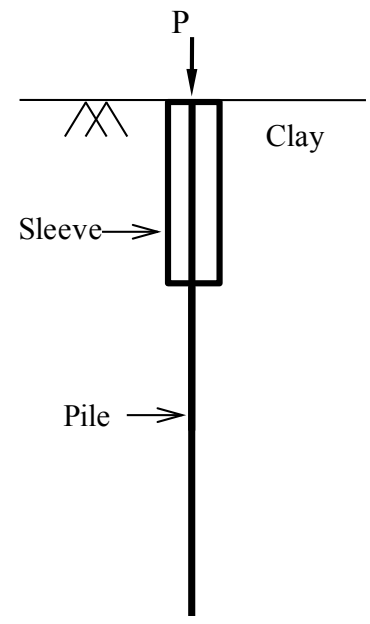

With sleeve

(L_Sleeve)

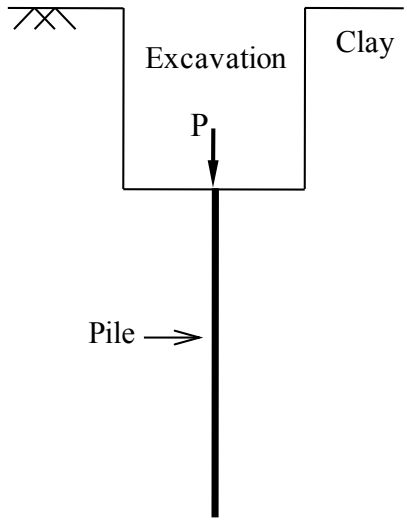

At formation level

(L_Excavation)

FIGURE 1. Configuration of pile load tests.

Pore pressure distribution was taken as hydrostatic in the initial state. Drainage boundary was considered at the top of the mesh.

\subsection{Constitutive Model and its Parameters}

Abaqus built-in model cannot capture the unique behaviour of soil properly. As soil is stress-state dependent material. Its stiffness depends upon stress level, strain level, and

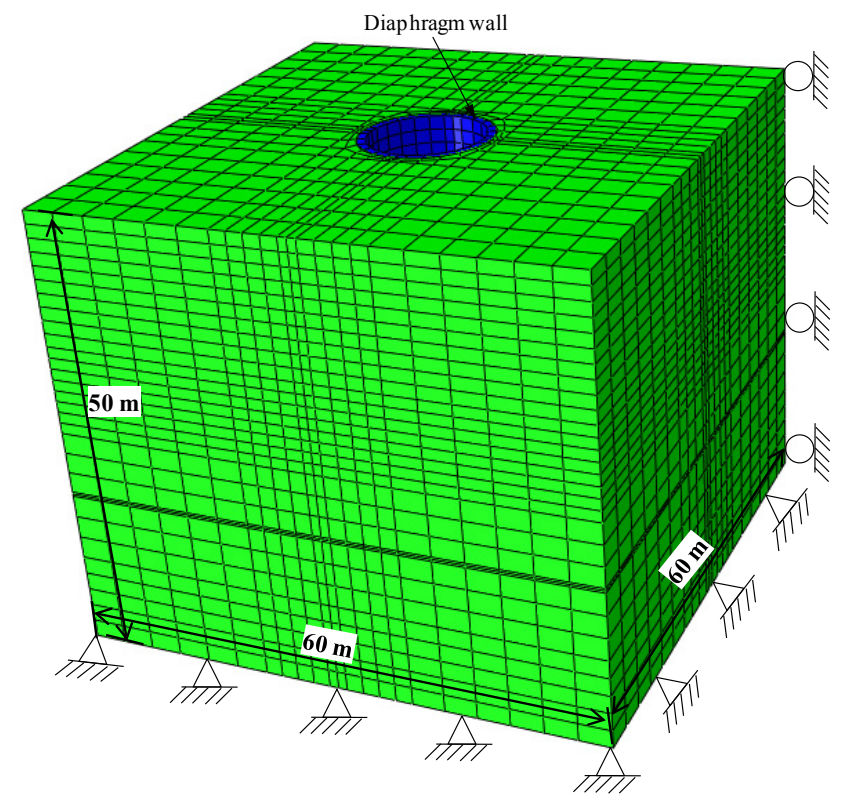

FIGURE 2. Abaqus mesh and boundary conditions. 
path. For this purpose, user sub-routine was implemented and an advanced hypoplastic model [11-12] was developed which can capture these behaviours of soil. In total, there are 10 important parameters. Five parameters $\left(N, \lambda^{*}, \kappa^{*}, \varphi_{c}\right.$, and r) consists the basic model and five additional parameters $\left(R, \beta_{r}, \chi, m_{T}\right.$, and $\left.m_{R}\right)$ are for intergranular strain concept [13].

In this study, the parameters for soft clay were adopted. Hypoplastic clay model parameters are given in Table 2. Ko (coefficient of lateral earth pressure at rest) was calculated by [14]'s equation.

$$
K_{\mathrm{o}}=\left(1-\sin ^{\prime}\right)
$$

The single pile, diaphragm wall, and props were assumed linear elastic with Young's Modulus and Poisson's ratio as $35 \mathrm{GPa}$ and 0.3 , respectively.

TABLE 2. Numerical simulation plan

\begin{tabular}{ll}
\hline Description & Value \\
\hline$\varphi^{\prime}$ & $22^{\circ}$ \\
$\lambda^{*}$ & 0.11 \\
$\kappa^{*}$ & 0.026 \\
$N$ & 1.36 \\
$R$ & 0.65 \\
$m_{\mathrm{R}}$ & 14 \\
$m_{\mathrm{T}}$ & 11 \\
$R$ & $1 \times 10^{-5}$ \\
$\beta r$ & 0.1 \\
$\chi$ & 0.7 \\
$e$ & 1.05 \\
\hline
\end{tabular}

\section{Effect of Excavation on Pile}

\subsection{Pile Capacity}

The objective of this research was to investigate the effects of stress relief on pile capacity in soft clay. For this purpose, three numerical pile load tests were conducted to compute the pile capacity. The failure criterion (Weltman 1980: ISSMFE 1985: BS 1986) was used to obtain load carrying capacity of the pile. According to which load at $10 \%$ normalized pile settlement is interpreted as ultimate bearing capacity. Using FOS equal to 3.0, dividing the ultimate load by FOS, the working load is calculated. Using this criterion, capacity of unsleeved and sleeved pile at ground level was found to be 9.8 MN and 13.3 MN. However, pile capacity after excavation at formation level was found to be $11.35 \mathrm{MN}$. Figure 3 illustrates the computed load-settlement curve for all the cases. The excavation depth and pile length are $12 \mathrm{~m}$ and $20 \mathrm{~m}$, respectively. The pile settlement is normalized by the pile diameter $(\mathrm{D}=0.8 \mathrm{~m})$ and the load is normalized by the ultimate load of sleeved pile. It is found that $Q_{\mathrm{LE}}$ is $85 \%$ of $Q_{\mathrm{LS}}$. The main reason of this reduction is the vertical overburden stress relief due to excavation. So it is concluded that when tests are conducted by using sleeve, pile capacity is over estimated. It is also found that $Q_{\mathrm{LG}}$ is $74 \%$ of $Q_{\mathrm{LS}}$ which is also less than $Q_{\mathrm{LE}}$. The reason of this increased capacity of unsleeved pile after excavation is that 


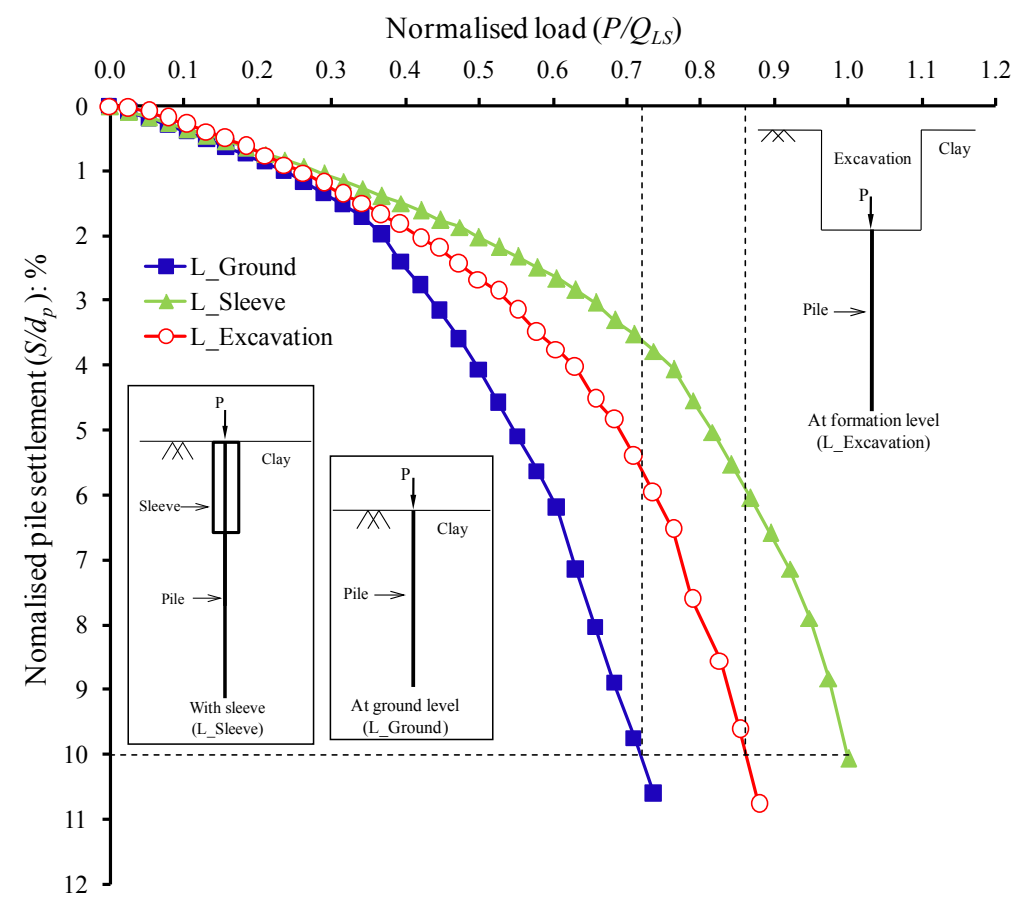

FIGURE 3. Load versus settlement curve.

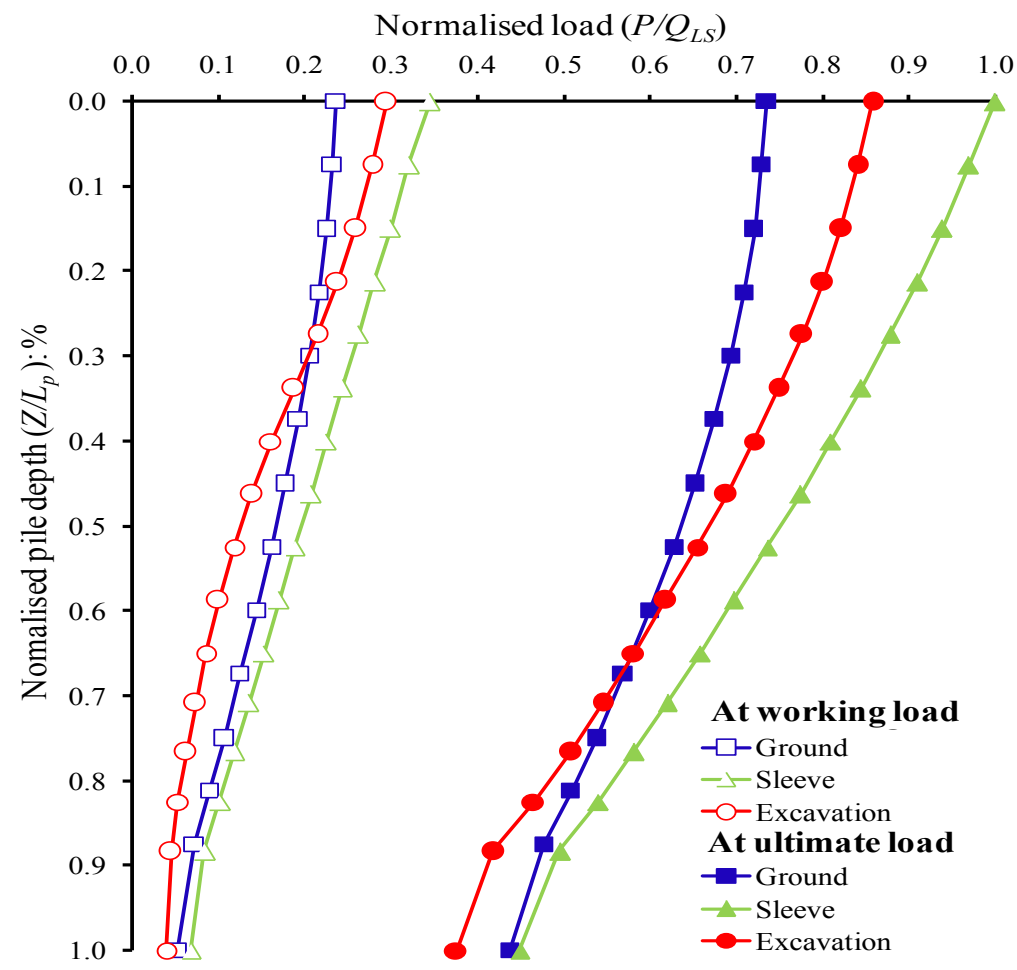

FIGURE 4. Normalized load distribution. 
soil stiffness and confining pressure increases as the depth increases so after excavation the soil particles around the pile are stiffer and the capacity is increased.

\subsection{Axial Load Distribution Along the Pile Length}

Figure 4 illustrates the axial load distribution along the pile length in all cases. Axial load is normalized by ultimate load capacity of sleeved pile $\left(Q_{\mathrm{LS}}\right)$ and depth below the ground surface $(Z)$ is normalized by the pile length (Lp). Figure shows that when test is conducted at ground level, at working load shaft carries about $77 \%$ load and the end bearing carries the remaining $23 \%$ load. But, when the load is increased and reaches the ultimate value end bearing contributes more than the shaft resistance. It is because shaft resistance has been fully mobilized and could not take more load so the end bearing carries the majority (about 60\%) of the total load. For sleeved pile, at working load shaft and end bearing carries about 80 and 20\% load respectively. But at ultimate load, shaft carries 55\% load which is still greater than that carried by end bearing. It is because confining pressure increases with depth and thus shaft resistance increases. Shaft of the unsleeved part of the pile which is at greater depth can carry more load as compare to the pile at ground level. However, after excavation, at working load shaft carries about $86 \%$ load. But when ultimate load is reached the load distribution is similar to the sleeved pile. But it can also be seen that in the case of ground level and excavation, the shaft resistance has been fully mobilized at the load less than $Q_{\mathrm{LS}}$ that is about 74 and $86 \%$ of $Q_{\mathrm{LS}}$, respectively.

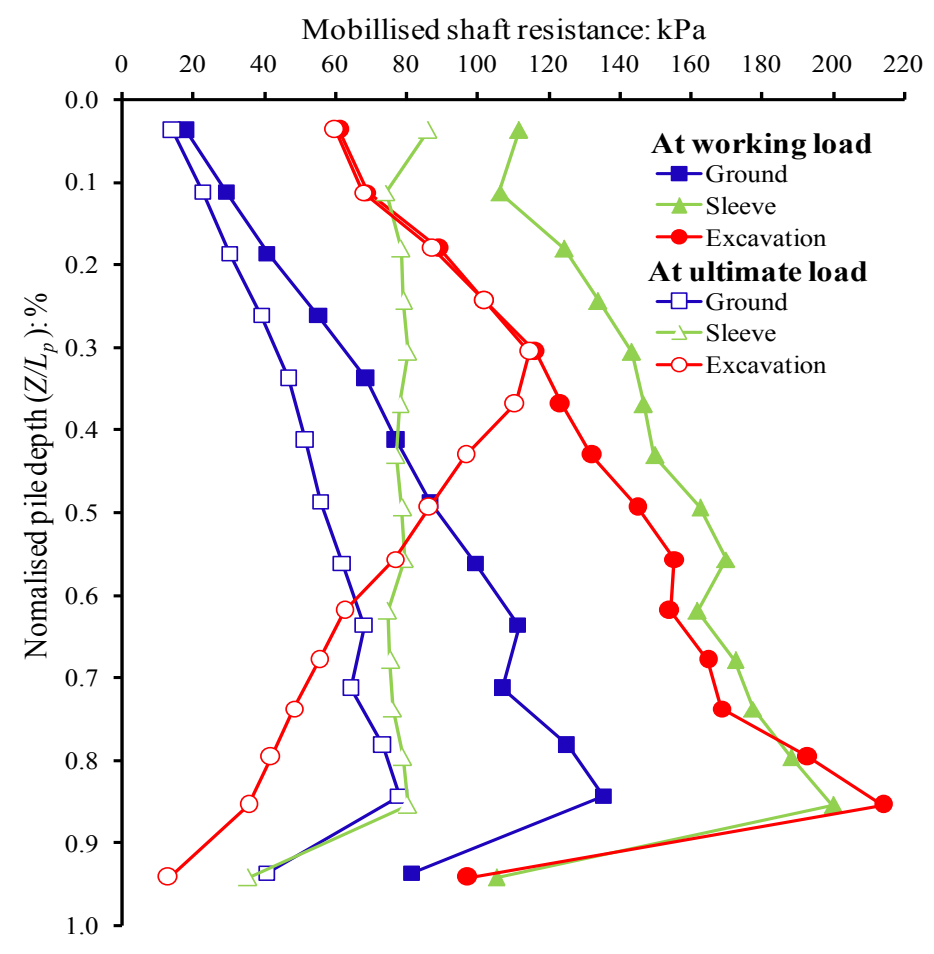

FIGURE 5. Side resistance along the pile. 


\subsection{Shaft Resistance Along the Pile Length}

Figure 5 shows the shaft resistance along the pile length for all cases. It can be observed from the figure that the shaft resistance increases with the depth. It is because the shaft resistance depends on the confining pressure which increases with depth. It can also be seen that shaft resistance is mobilized with increasing load as shaft resistance for ultimate load is more as compare to the working load in all cases. This figure also shows that after excavation when load is applied, initially shaft resistance reduces along the depth. It is because of the excavation stresses are released and the stress state of soil is changed. But when load is increased and it reaches ultimate value the shaft resistance is then mobilized hence increases with depth.

\section{Conclusions}

The following conclusions are drawn based on the computed results

- $Q_{\mathrm{LE}}$ is $85 \%$ of $\mathrm{Q}_{\mathrm{LS}}$ due to stress relief so when tests are conducted by using sleeve, pile capacity is over estimated.

- $Q_{\mathrm{LG}}$ is $74 \%$ of $\mathrm{Q}_{\mathrm{LS}}$ which is also less than $\mathrm{Q}_{\mathrm{LE}}$. The reason is that soil stiffness and confining pressure increases as the depth increases so after excavation the soil particles around the pile are stiffer and the capacity is increased.

- At ground level, at working load shaft carries about $77 \%$ load and the end bearing carried remaining 23\% load. But, when the load is increased and reaches the ultimate value end bearing contributes more than the shaft resistance. On the other hand, for sleeved pile, at working load shaft and end bearing carries about 80 and $20 \%$ load respectively. But at ultimate load, shaft carries 55\% load which is still greater than that carried by end bearing. While after excavation, at working load shaft carries about $86 \%$ load. When ultimate load is reached the load distribution is similar to the sleeved pile

- In the case of ground level and excavation, the shaft resistance has been fully mobilized at the load less than $Q_{\mathrm{LS}}$ that is about 74 and $86 \%$ of $Q_{\mathrm{LS}}$, respectively.

\section{Acknowledgements}

The authors would like to thank QUEST for the support.

\section{References}

1. Gang Z, Diao Y, Ng CWW. Parametric analysis of the effects of stress relief on the performance and capacity of piles in nondilative soils. Canadian Geotechnical Journal. 2011, 48(9), 13541363. DOI: 10.1139/t11-043.

2. Zheng Gang, Si Yuan Peng, Charles WW. Ng, Yu Diao. Excavation effects on pile behaviour and capacity. Canadian Geotechnical Journal. 201,, 49(12), 1347-1356. DOI: 10.1139/t2012-095.

3. Peng Siyuan. Influence of stress relief due to deep excavation on capacity of pile foundations. Ph.D Thesis. The Hong Kong University of Science and Technology. 2012. http://repository.ust. hk/ir/Record/1783.1-7722 
4. Leung CF, Chow YK, Shen RF. Behavior of pile subject to excavation-induced soil movement. Journal of Geotechnical and Geoenvironmental Engineering. 2000, 126(11), 947-954. DOI: 10.1061/(asce)1090-0241(2000)126:11(947).

5. Leung CF, Lim JK, Shen RF, Chow YK. Behavior of pile groups subject to excavation-induced soil movement. Journal of Geotechnical and Geoenvironmental Engineering. 2003, 129(1), 58-65. DOI: 10.1061/(asce)1090-0241(2003)129:1(58).

6. Finno RJ, Lawrence SA, Allawh NF, Harahap IS. Analysis of performance of pile groups adjacent to deep excavation. Journal of Geotechnical Engineering. 1991, 117(6), 934-955. DOI: 10.1061/ (asce)0733-9410(1991)117:6(934).

7. Mangnejo DA, Mangi N. The responses of an end-bearing pile to adjacent multipropped excavation: 3D numerical modelling. Civil Engineering Journal. 2019, 5(3), 552. DOI: 10.28991/ cej-2019-03091267.

8. Korff M, Mair RJ, Van Tol FA. F. Pile-soil interaction and settlement effects induced by deep excavations. Journal of Geotechnical and Geoenvironmental Engineering. 2016, 142(8), 04016034. DOI: 10.1061/(asce)gt.1943-5606.0001434.

9. He B, Lai Y, Wang L, Hong Y, Zhu R. Scour effects on the lateral behavior of a large-diameter monopile in soft clay: role of stress history. Journal of Marine Science and Engineering. 2019, 7(6), 170. DOI: 10.3390/jmse7060170.

10. Mair R, Williamson M. The influence of tunnelling and deep excavation on piled foundations. Geotechnical Aspects of Underground Construction in Soft Ground. 2014; 21-30. DOI:10.1201/ b17240-6

11. Mašín D. A hypoplastic constitutive model for clays. International Journal for Numerical and Analytical Methods in Geomechanics. 2005, 29(4), 311-336. DOI: 10.1002/nag.416.

12. Mašín D, Herle I. State boundary surface of a hypoplastic model for clays. Computers and Geotechnics. 2005, 32(6), 400-410. DOI: 10.1016/j.compgeo.2005.09.001.

13. Niemunis A, Herle I. Hypoplastic model for cohesionless soils with elastic strain range. Mechanics of Cohesive-frictional Materials. 1997, 2(4), 279-299. https://doi.org/10.1002/ (SICI)1099-1484(199710)2:4\%3C279::AID-CFM29\%3E3.0.CO;2-8

14. Liyanapathirana DS, Nishanthan R. Influence of deep excavation induced ground movements on adjacent piles. Tunnelling and Underground Space Technology. 2016, 52, 168-181. DOI: 10.1016/j.tust.2015.11.019. 